\title{
Restructuring a Liaison Program in an Academic Library
}

\section{Frada Mozenter, Bridgette T. Sanders, and Jeanie M. Welch}

\begin{abstract}
New technologies, an expanding universe of knowledge, and a more sophisticated user base influence not only how we provide access to information, but also how we define and organize ourselves in relation to the public. The J. Murrey Atkins Library of the University of North Carolina at Charlotte has endeavored to strengthen the relationship between the library and the teaching faculty by restructuring the library's liaison program. Concurrently, but independent of this redesign, three experienced reference librarians assessed their effectiveness as liaisons by conducting a survey of selected departments. A review of the development and implementation of the library's program, together with an assessment of the faculty survey, confirm that specific elements are prerequisites of an effective liaison program.
\end{abstract}

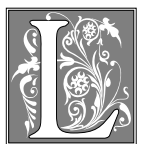

ibrarianship has undergone a rapid evolution since the advent of new technologies that provide both instant and remote access to information sources. New technologies, distributed learning, and distance education have altered the concepts of what libraries are and what academic librarians do. According to the "Information Literacy Competency Standards for Higher Education" of the Association of College and Research Libraries (ACRL), "Academic librarians coordinate the evaluation and selection of intellectual resources for programs and services; organize and maintain collections and many points of access to information; and provide instruction to students and faculty who seek information. ${ }^{11}$ At the same time as this elec- tronic revolution, academic libraries are undergoing organizational changes-redefining and reassigning responsibilities throughout the organization. One area that libraries are examining in light of changing roles and expectations is the concept of liaison services to teaching faculty. A restructuring of the library liaison program at a state university provides an example of organizational change within this rapidly changing technological environment.

The University of North Carolina at Charlotte (UNC Charlotte) is a comprehensive, regional institution that gained university status within the University of North Carolina System in 1965. At present, it has approximately 16,000 students. The campus is served by the J. Murrey Atkins Library, a centralized li-

Frada Mozenter is a Professor and Reference Librarian, Bridgette T. Sanders is an Associate Professor and Reference Librarian, and Jeanie M. Welch is a Professor and Reference Librarian in the J. Murrey Atkins Library at the University of North Carolina at Charlotte; e-mail: flmozent@email.uncc.edu, btsander@email.uncc.edu, and jmwelch@email.uncc.edu, respectively. 
brary facility with a small branch collection in the College of Architecture. The J. Murrey Atkins Library houses more than 694,000 volumes and almost 900,000 government documents, and carries almost 5,000 current subscriptions. The library staff consists of twenty-four librarians. A restructuring of the liaison program at Atkins Library prompted a review of the previous liaison program, a survey of selected academic departments, and an analysis of the new program's implementation.

\section{Literature Review and Online Survey of Academic Library Liaison Programs}

As a result of the implementation of a restructured liaison program, one of the authors conducted a literature review of liaison responsibilities, including guidelines for liaisons. ${ }^{2}$ The ARL Office of Management Services developed the most extensive survey of liaison responsibilities in $1992 .{ }^{3}$ Four major areas were reviewed: the liaison within the organizational framework, the definition of $l i$ aison, coordination of liaison services, and the responsibilities of the liaisons. Although collection development was identified by most libraries as their primary activity, the survey revealed that most of the guidelines documenting liaison activity contained common themes. These included statements of purpose, identification of a target group the liaisons were to serve, the role of departmental representatives, statements covering communication between liaisons and departments, and summaries of the range of services the liaisons were to provide. All these points can be extended to liaison services beyond that of collection development. Another important aspect of the ARL survey was recognition that the need for, and scope of, liaison services expands as physical collections make way for electronic collections available via remote access. Decentralizing collections and changing from print to electronic resources require more communication and more instruction.
Other surveys reported on the liaison program as an important promotion and marketing device. ${ }^{4}$ According to Cynthia C. Ryans, Raghini S. Suresh, and Wei-Ping Zhang, "a liaison programme is designed to provide a communication link between the library and the academic community to enhance the image of the library. ${ }^{\prime 5}$ But liaison work goes far beyond that definition. Liaison programs provide communication to teaching faculty about new library services and strengthen the role of the librarian in facilitating access to the wide range of resources that are available.

To examine current liaison programs, one of the authors sent out a query on the listserv LIBREF-L. Nine responses were received (eight from U.S. institutions and one from a foreign institution). ${ }^{6}$ Of the eight U.S. institutions, five were comparable in size to UNC Charlotte. All of the libraries had established some type of liaison program. Although it was not always clearly stated which staff members were involved, it appeared that about half of the respondents restricted these responsibilities to reference librarians and the rest included both public services and technical services staff. Three respondents specifically noted that liaison assignments were based (as much as possible) on academic degrees, work experience, and/or interest, a finding also reflected in the literature survey. Most reported a full range of responsibilities, although not all respondents provided detailed information. Duties that were noted included: general communication with the teaching faculty in their department(s), including apprising them of library resources and policies and keeping the library administration abreast of departmental needs; assistance with budget reports, collection development, and library instruction; assistance with accreditation reports; and specialized help, when needed.

\section{Previous Liaison Responsibilities of Librarians at UNC Charlotte}

Prior to implementation of the new program at UNC Charlotte, all liaison responsibilities were handled by eight subject 
specialists within the Reference Unit. Although liaisons differed in their approaches, traditional liaison responsibilities have been, and continue to be, the following:

- in-depth reference/research service;

- electronic search services;

- library instruction;

- course proposal and accreditation reports;

- reference collection development.

In-depth reference and research service encompasses assisting teaching faculty and students with extensive research, including electronic literature searching, citation searching, and discussions of research methodology. In-depth reference service has become more imperative as the growth in electronic resources has increased patron awareness of and access to resources. The liaison librarians are considered the "experts" in their disciplines and are expected to keep abreast of new resources and emerging technologies.

The electronic services segment of the liaison program has three major components: selecting new services; training staff, teaching faculty, and students; and providing mediated searching to teaching faculty. Recommendations for new electronic search services are handled by the library's Electronic Collections Advisory Committee (ECAC). Liaisons may initiate action by contacting a teaching faculty member and seeking input or by forwarding a request to ECAC. In other cases, teaching faculty suggest the service to the liaison. ECAC compiles a list of recommendations, but the final decisions rest with the director of library services. However, consortial agreements on the purchase of electronic search services have priority over local recommendations. The reference unit coordinator of electronic search services coordinates training for such services within the unit. When a new service is acquired, the coordinator contacts the appropriate subject specialist and requests development of an end-user guide and staff training. Subsidized mediated searching of DIALOG databases also is provided by liaisons for the teaching faculty. However, because Web-based services permit easy access, most teaching faculty search files themselves. Liaison responsibilities for electronic search services include keeping teaching faculty informed of new services or changes to existing services, disseminating passwords, and assisting teaching faculty with search strategies.

Library instruction remains an important part of the liaison program and an important service to the library's patrons. The goal of library instruction is to provide instruction that effectively supports university programs of teaching, research, and service for teaching faculty and students. Formal instruction facilitates effective research through lectures and demonstrations of print and nonprint resources for individual class assignments and programs supported by the university. In most cases, teaching faculty initiate requests for library instruction. Other liaisons initiate the call for instruction each semester, using print or e-mail notification and request forms. Teaching faculty and liaisons work together to determine the best format and resources for providing the needed information to students. Whenever possible, the instruction is based on a specific research assignment and may include the preparation of print handouts, webliographies, or class-specific Web sites. Another form of library instruction is that of general library tours conducted by the liaisons.

The review of course proposals and the preparation of accreditation reports include assisting departments in planning new courses and programs and ensuring that supporting resources are available. UNC Charlotte has campuswide curriculum committees, and all proposals for new courses or new programs or any changes to existing curricula or programs must be submitted to a committee for initial approval. When the proposal is being prepared at the departmental level, it also must be submitted to the liaison librarian to determine if sufficient resources are available. 
In general, collection development responsibilities are restricted to the print reference collection, which consists of approximately 20,000 monographs and index volumes. Reference collection development is under the direction of a reference librarian who serves as reference collection development coordinator. There is a separate budget for reference materials that is allocated to the subject areas. Subject liaisons select titles to be added to the collection, and titles are approved by the reference collection development coordinator. Additions to or deletions of print indexes are recommended by the subject liaisons with the final decision made by the reference librarians as a group.

In terms of collection development for the circulating collection, the titles are approved by the library representatives from the teaching faculty within each department or college and are purchased using funds that had been allocated on a formula based on enrollment. However, two exceptions to this arrangement are business and women's studies. Titles for the circulating collection of the Belk College of Business Administration are selected by the business subject specialist within the Reference Unit. The selection process is done through the conventional methods of reviewing publishers' catalogs and standard reviewing sources (e.g., Choice cards), requests from the college library representative, and a review of standard acquisitions lists such as the Harvard Business School Core Collection. The women's studies program at UNC Charlotte offers a minor degree program. Unlike departments that have funds allocated to them, monies for the women's studies collection come from a general fund and stay under the library's auspices. Two major review sources are consulted on a regular basis-The Women's Review of Books and Choice. The book review sections of Psychology of Women Quarterly, Women's Studies, Signs, Journal of Women's History, and Gender and Society also are consulted. $^{\text {? }}$

\section{The Restructured Library Liaison Program}

In 1998, a working group consisting of the head of technical services, the head of collection development, the coordinator of reference services, and the head of research data services was charged by the library director with developing recommendations for strengthening the role of library liaisons. The working group formulated a two-page list of thirty-one responsibilities that expanded the definition of liaison responsibilities to include any subject-oriented contact with departments and colleges. The Reference Unit reviewed this document, organized it into functional areas, and suggested changes to meet concerns of balance and accountability. The final report was approved by the Library Council, which consists of the library director and senior managers. It also was endorsed by the university-wide Library Advisory Faculty Committee.

A report was issued that delineated library liaison responsibilities, using the outline suggested by the Reference Unit. It included the following goals: ${ }^{8}$

- to develop a strong collaborative program between the library and academic units;

- to develop a collaborative framework to support the library's instructional mission;

- to provide a conduit for the library to communicate and discuss library issues and concerns with the faculty;

- to develop a proactive stance toward information resources for the larger university community;

- to participate in and support faculty development efforts with regard to electronic and other information resources.

The report listed liaison responsibilities in the following categories: ${ }^{9}$

- general responsibilities (e.g., communication and training);

- reference service;

- library instruction;

- collection development and management;

- curriculum development (curriculum proposals and accreditation reports). 
The working group assigned librarians and support staff from all library departments as liaisons or adjunct liaisons, set up a model for governance based on a Liaison Steering Group, and outlined a training program. (Adjunct liaisons did not have all of the responsibilities of the primary liaisons.) Library liaisons and adjunct liaisons were organized into three liaison subject groups-sciences, social sciences, and humanities and architecture. Conveners were appointed for each group to serve on the Steering Group and to provide leadership for their subject group. The Steering Group included the heads of collection development, technical services, and the information commons, and the conveners of the liaison subject groups.

The month-long training program consisted of four two-hour sessions, with handouts provided for each session. The first session overviewed the program's goals, expectations, and financial information, including the materials budget, the accounting system, and budget access and interpretation. The second session overviewed all aspects of acquisitions, including monograph and serials ordering, collection management tools (e.g., Blackwell's Collection Manager), electronic products, the university approval plan, gifts, and preservation issues (reordering or replacement of damaged materials). The library recently had revised its collection development policy, stating that "The library will define, develop, and manage its collection in cooperation with each academic unit through a mutually acceptable mechanism." It further stated that "Different arrangements may result among departments." ${ }^{10}$

The third session overviewed library services in collection access (circulation), interlibrary loan, the OPAC (the library was implementing a new Web-based OPAC while training was under way), government documents, special collections, and document delivery (e.g., UnCover Reveal). The fourth session overviewed reference services, bibliographic instruction, and the handling of new course and program proposals and accreditation reports. A brief evaluation survey was distributed two months after the training had been completed. Information sessions for deans, department chairs, and library representatives from the teaching faculty also were conducted.

After the four training sessions had been completed, three experienced librarians reviewed the new program's development and implementation. The review concentrated on four areas:

- organization;

- communication;

- training;

- evaluation.

As with the restructuring of any librarywide program, the first thing to do is to adopt a thorough organizational plan. This affects both individual responsibilities and the program's general operation and structure. In terms of the restructured liaison program, the liaison areas, responsibilities of the conveners, and the Steering Group were well defined. However, input from experienced liaisons may have facilitated resolution of the following questions about liaison qualifications and responsibilities:

- What are the criteria for appointment as a liaison or adjunct liaison (e.g., professional experience, education, present job responsibilities)?

- What are the responsibilities on nonpublic services staff in terms of reference assistance and library instruction?

- Can liaisons select their responsibilities, and what effect might this have on public services?

- Can liaisons unilaterally opt out of the program (and, if so, how)?

- What is the relationship between liaisons and adjunct liaisons?

Second, it is important to address the issue of both internal and external communication. As with any complex, librarywide initiative, changes in personnel (e.g., unexpected vacancies and new hires) affect the composition of the liaison program. Notifying liaisons that there have been changes in their responsibilities or that personnel changes necessitate 
reassigned liaison responsibilities must be a high priority. In terms of external communication with the campus community, administrators of a restructured liaison program must have a clear policy on communications with colleges and departments. Communication considerations include:

- campuswide publicity (e.g., announcing the program, announcing any personnel changes);

- guidelines for liaisons when communicating with individual colleges and departments.

To ensure that the new program meets its stated objectives, evaluations must be timely, comprehensive, and informative.

Third, issues related to training must be addressed. Both experienced and new liaisons attended the same training sessions. Although it was stated that the four training sessions were to ensure the same core competencies for all liaisons, they were repetitive for experienced liaisons. A suggested structure might be an introductory session for everyone, information-based workshops geared to the new participants, an "update" session for everyone on new policies and services being introduced, and, finally, a session for everyone detailing future training within their liaison groups. Areas in which training may be needed include:

- use of collection management statistical tools;

- use of selection resources;

- library instruction;

- reference sources (both print and electronic) and reference assistance;

- collection analysis for course proposals and accreditation reports.

Fourth, there is the issue of evaluation. To ensure that the new program meets its stated objectives, evaluations must be timely, comprehensive, and informative. First, evaluation should be an ongoing process, preceded by a needs assessment for both faculty and liaisons. Second, the training received by liaisons also needs to be assessed. Such assessment should include the quality and scope of the workshops, perceptions of their effectiveness, and the impact of the training on the skills that liaisons brought to the program. In addition, evaluation should include a means for liaisons to request specific areas and types of sessions for further training. ${ }^{11}$ Third, a separate evaluation of the teaching departments should be conducted to include the effectiveness of all aspects of the program and satisfaction with liaisons. Both such evaluations should be built into the structure of the liaison program, with all aspects undergoing periodic review and analysis.

One of the first evaluative issues may be that of collection development. The present policy allows each department and liaison to develop its own process. ${ }^{12}$ The impact of such an open policy will need to be assessed. How do multiple arrangements affect liaisons (especially liaisons with a number of departments, each handled differently)? How do different arrangements impact the overall quality of the collection? And how do new liaisons from nonpublic service areas incorporate liaison responsibilities into their jobs?

In summation, progress must be made on a number of issues. To ensure the viability of the new program, the Steering Committee must develop additional training sessions for liaisons constructed within a framework best suited to each application. The sessions should be timely and include specific goals, objectives, and activities; provide better communication; better define and document policies and procedures; refine organizational structure and processes; and develop well-constructed assessment tools.

\section{Survey of Teaching Faculty}

Concurrent with, but independent of, liaison training, three experienced liaisons were interested in taking the opportunity to assess their effectiveness as liaisons. A ten-question survey was developed and sent to the teaching faculty $(n=118)$ in ten departments, nine in the College of 


\begin{tabular}{|lc|}
\hline \multicolumn{2}{|c|}{$\begin{array}{c}\text { TABLE 1 } \\
\text { Results of Faculty Survey }\end{array}$} \\
\hline \hline Information Provided by Liaisons & $\begin{array}{r}\text { Percentage of Faculty Reporting } \\
\text { Receiving Information }\end{array}$ \\
\hline Information about electronic services & $86.2 \%(\mathrm{n}=25)$ \\
Library instruction & $75.8 \%(\mathrm{n}=22)$ \\
General library information & $68.9 \%(\mathrm{n}=20)$ \\
Mediated searches & $48.2 \%(\mathrm{n}=14)$ \\
Notification of new titles in the reference collection & $48.2 \%(\mathrm{n}=14)$ \\
Resources related to respondents' research & $44.8 \%(\mathrm{n}=13)$ \\
Other (e.g., Web links and assistance with ILL) & $20.6 \%(\mathrm{n}=6)$ \\
\hline
\end{tabular}

Arts and Sciences and one in the Belk College of Business Administration. Surveyed departments comprised the liaison groups of three of the researchers of this study and one other experienced liaison. The departments were selected on the basis of past stability in relation to their liaison, as well as on the proposed program changes. The liaisons of the surveyed departments had held liaison responsibilities for periods ranging from two to nineteen years. In addition, all liaisons had a graduate or undergraduate degree in one of their areas.

The survey was sent to all full-time teaching faculty, both tenured and untenured, and to the chairs of the departments of criminal justice, dance and theater, foreign languages, marketing, music, philosophy, political science, social work, and sociology/anthropology. Three weeks were given for completion. To ensure candor, questionnaires were bundled by department and returned to a liaison other than the one for that department. The questions were based primarily on the traditional liaison services currently provided at UNC Charlotte. The questions focused on four major areas:

- communication;

- library instruction;

- general assistance;

- professional competency.

Respondents were asked to check the appropriate answer (e.g., "Satisfactory" or "Needs Improvement"). Space also was provided for suggestions for improvement or general comments. ${ }^{13}$
Of the 118 questionnaires sent, fortyseven were returned (a return rate of approximately $39.8 \%$ ). Of the total, 61.7 percent $(n=29)$ indicated that they or their department had been contacted by their liaison. Of these, 58.6 percent $(n=17)$ said they were contacted "very often" and 37.9 percent $(n=11)$ "somewhat often." The most frequent form of communication was e-mail $(89.9 \%)(n=26)$. Eighty-seven percent responded that the liaison had kept them informed of services. The type of information provided is shown in table 1 . Twenty of the forty-seven respondents $(42.5 \%)$ reported that the liaison had provided library instruction for their students, and eighteen of them $(90 \%)$ were satisfied with the teaching and presentation skills of the librarian. Eighteen of the respondents $(90 \%)$ indicated that a Web page or handout had been developed for the class, and nineteen $(95 \%)$ reported satisfaction with the handouts or Web pages.

The necessity of communication was made clear by both the critique of the restructured program and the evaluation of the survey.

Overall, respondents appear satisfied with the service level offered by their liaison. Of the twenty-nine respondents who said they had received some form of communication (and one who did not receive communication), all indicated they see the liaison as "available and approachable"; twenty-six $(89.9 \%)$ responded that the liaison was "available 
to their students." All stated that they regarded their liaison as "satisfactory" as to the level of knowledge in respect to information sources in their discipline. Twenty-seven $(93.2 \%)$ rated the liaison as "satisfactory" in the areas of reference competency and communication skills. Twenty-six (89.9\%) reported satisfaction with the quality of work provided by the liaison. Overall, all respondents who had contact with their liaison rated them as "satisfactory." Some respondents provided written responses to questions when they did not think the existing categories were adequate. Others provided additional information as "comments." The respondents in departments with the most liaison interaction indicated the highest satisfaction level in the most areas. Although the departments surveyed had very different needs, the survey results seem to support the thesis that, in general, a proactive liaison provides the greatest satisfaction level to respondents.

\section{Conclusions and Recommendations}

A critique of the planning and implementation of the restructured library liaison program, together with an assessment of the faculty survey, affirms that certain elements are prerequisites for an effective liaison program. These include a comprehensive vision statement, clear and concise goals and objectives, a well-organized and detailed process for executing the proposal, a distinct framework within which the program operates, well-defined responsibilities, focused training, and regular evaluation of the liaison program's internal processes and teaching faculty satisfaction. One final element, and perhaps of greatest import, is that of communication. The necessity of communication was made clear by both the critique of the restructured program and the evaluation of the survey. In regard to the library program, too often critical information was not disseminated. In turn, the survey seemed to support the thesis that proactive liaisonship provides the greatest satisfaction, even when allowing for the departments' individual needs and the varying skills and styles of the liaison. In summation, an effective liaison program should be comprehensive, yet detailed. It should be structured, yet provide room for flexibility. It should be well grounded in theory, yet based on proven experience. It also needs to be reevaluated on a regular basis and restructured to meet the changing needs of the teaching departments.

\section{Notes}

1. ACRL Task Force on Information Literacy Competency Standards, "Information Literacy Competency Standards for Higher Education" (Chicago: ACRL, 2000). Cited April 6, 2000. Available online from: http://www.ala.org/acrl/ilintro.html.

2. Reference and Adult Services Section, Collection Development and Evaluation Section, Liaison with Users Committee, "Guidelines for Liaison Work," RQ 32 (winter 1992): 198-204; Connie Wu, Michael Bowman, Judy Gardner, Robert G. Sewell, and Myong Chung Wilson, "Effective Liaison Relationships in an Academic Library," College E Research Libraries News 55 (May 1994): 254, 303; Marta A. Davis and M. Kathleen Cook, "Implementing a Library Liaison Program: Personnel, Budget, and Training," Collection Management 20, no. 3-4 (1996): 157-65.

3. Liaison Services in ARL Libraries (Washington, D. C.: ARL Office of Management Services, 1992).

4. Ibid.

5. Cynthia C. Ryans, Raghini S. Suresh, and Wei-Ping Zhang, "Assessing an Academic Library Liaison Programme," Library Review 44, no. 1 (1995): 14.

6. Jeanie M.Welch, "Liaison Librarians," in Discussion of Library Reference Issues. Cited October 21, 1999. Available online from: libref-1@listserv.kent.edu.

7. For further information on collection development in women's studies, see Meghan Conway, Stephanie Gonder, and Michele Butler, "Women's Studies in Academic Library Collections," Current Studies in Librarianship 19 (spring-fall 1995): 70-84; Mark W. Emery, "Considerations Regarding Women's Studies Collection Development in Academic Libraries," Collection Management 10, no. 1-2 (1988): 85-94; Cynthia Faries, "Collection Evaluation in Women's Stud- 
ies: One Model for Learning the Process," Collection Building 13, no. 4 (1994): 1-7; Women's Studies Collection Development Policies (Chicago: ACRL, Women's Studies Section, 1992); Susan Hildenbrand, ed., Women's Collections: Libraries, Archives, and Consciousness (New York: Haworth Pr., 1986).

8. J. Murrey Atkins Library, "Library Liaison Program" (Univ. of North Carolina at Charlotte, 1999, photocopy), 1

9. Ibid., 3.

10. — "Collection Development Principles: Explanations and Recommendation" (Univ. of North Carolina at Charlotte, n.d., photocopy), 2.

11. For a discussion of the practical aspects of staff training, see Deborah Grealy, Lois Jones, Kostas Messas, Kathleen Zipp, and Lise Catalucci, "Staff Development and Training in College and University Libraries: The Penrose Experience," Library Administration \& Management 10 (fall 1996): 204-9.

12. J. Murrey Atkins Library, "Collection Development Principles," 1-2.

13. For another recent survey of faculty perceptions of liaison service, see Zheg Ye (Lan) Yang, "University Faculty's Perception of a Library Liaison Program: A Case Study," Journal of Academic Librarianship 26 (Mar. 2000): 124-28. 